\title{
Providing optimal cardiovascular and thoracic critical care in the Great White North
}

\author{
Hadi Toeg, MD, MSc
}

\author{
From the University of Ottawa Heart Institute, University of Ottawa, Ottawa, Canada. \\ Disclosures: Author has nothing to disclose with regard to commercial support. \\ Received for publication Feb 4, 2015; revisions received May 21, 2015; accepted for publication May 29, 2015; \\ available ahead of print June 24, 2015. \\ Address for reprints: Hadi Toeg, MD, MSc, 40 Ruskin St, Ottawa, Ontario, Canada K1Y 4W7 (E-mail: htoeg@ \\ ottawaheart.ca). \\ J Thorac Cardiovasc Surg 2015;150:463-4 \\ $0022-5223 / \$ 36.00$ \\ Copyright (C) 2015 by The American Association for Thoracic Surgery \\ http://dx.doi.org/10.1016/j.jtcvs.2015.05.058
}

Cardiac surgery is a wonderful specialty of complex reparative operations followed by intensive postoperative care. As a cardiac surgical resident training in Canada (the Great White North), I am just past the halfway point of surgical training. Cardiac surgery training programs in Canada consist of direct-entry 6-year programs that, in addition to cardiovascular and thoracic surgical training, include cardiology training and 12 months of academic enrichment. During my first few years of residency, I was allotted several elective rotations. Additional cardiac surgical rotations obviously are a great choice; however, I felt compelled to immerse my experience in critical care and the nuances surrounding patients with medically complex conditions. The immense teamwork and motivation that one experiences in the operating room can be even more powerful in the intensive care unit (ICU). Although historically surgeons and residents have been intimately involved in the ICU, the advent of "closed" surgical units has led to decreased exposure for residents. The model of closed medical and surgical ICUs has dominated since the late 1990s, after the demonstration of better clinical outcomes. ${ }^{1-4}$ In Canada more than $70 \%$ of ICUs are closed units ${ }^{5}$; however, my institution's cardiothoracic ICU practices a teambased approach with surgeon leadership, even though it is formally titled as a closed unit.

The ICU environment generates a sense of responsibility, trust, and belonging, and it creates an overall wonderful environment to work and learn. I believe that all surgical trainees should be encouraged to train and learn from our ICU physicians, some of whom are surgeons or anesthesiologists. Every clinical encounter, procedure, family meeting, or code blue further educates us as physicians and as surgeons. Although I may seem to be painting a perfect picture of patient care, struggles will be encountered. The most difficult situation occurs when there is a polarization of expectations in patient care between surgeons and intensivists. This may occur when a high-risk patient undergoes surgery and is faced with a significant postoperative complication, such as a major stroke, kidney failure requiring

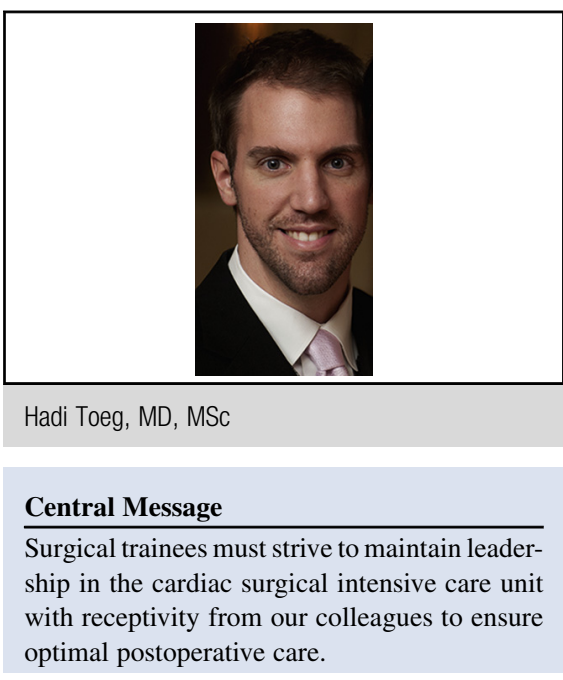

See Editorial Commentary page 464.

dialysis, or respiratory failure. The surgeon's preoperative patient interaction typically influences the intensity of postoperative care that the patient should receive. This approach is ubiquitous across all levels of medicine; after a major unintended complication, however, a discrepancy in the level of care between surgeons and intensivists can arise. Unfortunately, this harmonious environment becomes disjointed because there are two medical teams-each with its captain-that, despite both providing appropriate care, have different directions; for instance, the surgeon's team may advocate full support and treatment, whereas the intensivist's team may advocate conservative approaches or consider palliation, or this scenario may be interchanged.

Fortunately, there is a solution. I have observed and participated on both sides. Understanding of the current clinical situation, full disclosure to the patient's family, and finally exhaustive communication between the surgeon and intensivist are paramount. Both teams will then amalgamate and provide patient-centered care. Although preoperative checklists and surgical pauses have become the standard of care, 6,7 patients with high-risk features or those undergoing complex operations should have more preoperative planning and discussion among all the members of the surgical team: a detailed surgical plan and intensive care map is needed, including alternative treatment plans if complications arise. Preferably, this multidisciplinary consultation should be performed far in advance to improve clinical effectiveness and resource allocation. The concept of a "heart team," advocated 
previously for cases of transcatheter aortic valve replacement and complex coronary artery disease, ${ }^{8,9}$ should also be formalized in optimizing high-risk patients' perioperative outcomes. This includes a surgical leader with an unbiased mind who is receptive to suggestions and opinions from all members of the team.

Because of the demanding surgical and technical skills that trainees require, there is less time spent undergoing formal training in the ICU; furthermore, the emergence of closed units has deterred residents from participating directly in daily ICU patient care. Trainees should therefore engage themselves in daily ICU activities, partaking in formal ICU rotations, or should consider fellowship training in the ICU (Canada) or cardiothoracic-specific surgical critical care training (United States). ${ }^{10}$ As more surgeon trainees are exposed to the ICU setting, perioperative procedural, communication, and leadership skills will be refined, leading to a higher caliber of patient-centered care. Finally, as young surgeons training in an ever-evolving field with such innovations as catheter-based strategies and minimally invasive surgery, we must strive to maintain leadership in the ICU with receptivity from our colleagues to ensure optimal postoperative care.

\section{References}

1. Kumar K, Zarychanski R, Bell DD, Manji R, Zivot J, Menkis AH, et al; Cardiovascular Health Research in Manitoba Investigator Group. Impact of 24-hour inhouse intensivists on a dedicated cardiac surgery intensive care unit. Ann Thorac Surg. 2009;88:1153-61
2. Carson SS, Stocking C, Podsadecki T, Christenson J, Pohlman A, MacRae S, et al. Effects of organizational change in the medical intensive care unit of a teaching hospital: a comparison of 'open' and 'closed' formats. JAMA. 1996; 276:322-8.

3. Ghorra S, Reinert SE, Cioffi W, Buczko G, Simms HH. Analysis of the effect of conversion from open to closed surgical intensive care unit. Ann Surg. 1999;229: 163-71.

4. Morrow DA, Fang JC, Fintel DJ, Granger CB, Katz JN, Kushner FG, et al; American Heart Association Council on Cardiopulmonary Critical Care, Perioperative and Resuscitation; Council on Clinical Cardiology; Council on Cardiovascular Nursing; Council on Quality of Care and Outcomes Research. Evolution of critical care cardiology: transformation of the cardiovascular intensive care unit and the emerging need for new medical staffing and training models: a scientific statement from the American Heart Association. Circulation. 2012;126:1408-28.

5. Heyland DK, Cook DJ, Dodek PM. Prevention of ventilator-associated pneumonia: current practice in Canadian intensive care units. J Crit Care. 2002;17: $161-7$.

6. Urbach DR, Govindarajan A, Saskin R, Wilton AS, Baxter NN. Introduction of surgical safety checklists in Ontario, Canada. N Engl J Med. 2014;370:1029-38.

7. Semel ME, Resch S, Haynes AB, Funk LM, Bader A, Berry WR, et al. Adopting a surgical safety checklist could save money and improve the quality of care in U.S. hospitals. Health Aff (Millwood). 2010;29:1593-9.

8. Hillis LD, Smith PK, Anderson JL, Bittl JA, Bridges CR, Byrne JG, et al; American College of Cardiology Foundation/American Heart Association Task Force on Practice Guidelines. 2011 ACCF/AHA guideline for coronary artery bypass graft surgery: executive summary: a report of the American College of Cardiology Foundation/American Heart Association Task Force on Practice Guidelines. J Thorac Cardiovasc Surg. 2012;143:4-34. Erratum in: J Thorac Cardiovasc Surg. 2012;143:1235.

9. Nishimura RA, Otto CM, Bonow RO, Carabello BA, Erwin JP 3rd, Guyton RA, et al; American College of Cardiology; American College of Cardiology/American Heart Association, American Heart Association. 2014 AHA/ACC guideline for the management of patients with valvular heart disease: a report of the American College of Cardiology/American Heart Association Task Force on Practice Guidelines. J Thorac Cardiovasc Surg. 2014;148:e1-132.

10. Katz NM. The evolution of cardiothoracic critical care. J Thorac Cardiovasc Surg. 2011;141:3-6.

\title{
EDITORIAL COMMENTARY
}

\section{Cardiac critical care: Surgical trainees want and need expertise}

\author{
Kanwal Kumar, MD, MSc, FRCSC, Rohit K. Singal, MD, MSc, FRCSC, and \\ Rakesh C. Arora, MD, PhD, FRCSC
}

See related editorial on pages $463-4$.

From the Cardiac Sciences Program, I.H. Asper Clinical Research Institute, St. Boniface General Hospital, Winnipeg, Manitoba, Canada.

Disclosures: Authors have nothing to disclose with regard to commercial support.

Received for publication June 28, 2015; accepted for publication July 1, 2015; available ahead of print July 26,2015

Address for reprints: Rakesh C. Arora, MD, PhD, FRCSC, Cardiac Sciences Program, 369 Tache Ave, CR 3012, St Boniface General Hospital, I.H. Asper Clinical Research Institute, Winnipeg, Manitoba, Canada R2H 2A7 (E-mail: rakeshcarora@gmail.com).

J Thorac Cardiovasc Surg 2015;150:464-6

$0022-5223 / \$ 36.00$

Copyright $\odot 2015$ by The American Association for Thoracic Surgery http://dx.doi.org/10.1016/j.jtcvs.2015.07.001
Through the past 10 years, there has been a formal call for an evolution in the perioperative care for patients after cardiac surgery. ${ }^{1,2}$ For example, in 2012 the Journal of Thoracic and Cardiovascular Surgery added a dedicated section devoted to perioperative management content.

In this issue of the Journal, Dr Toeg has provided an insightful trainee perspective

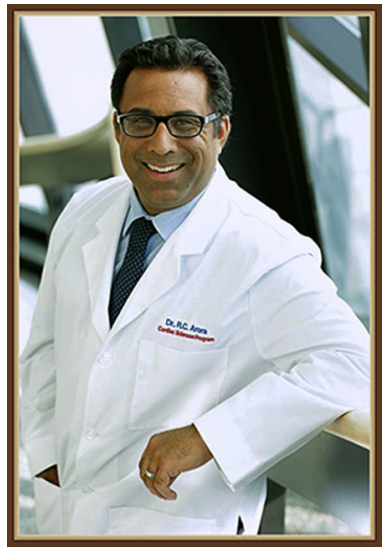

